\title{
Avances y límites de la expansión agraria argentina: crecimiento económico y distribución de la riqueza rural en Entre Ríos (1860-1892)
}

\section{Advances and limits of agrarian expansion in Argentina: economic growth and rural wealth distribution in Entre Ríos (1860-1892)}

\author{
JULIO DJENDEREDJIAN \\ Instituto Ravignani (Universidad de Buenos Aires), CONICET y \\ Universidad de Belgrano, Argentina \\ ROBERTO SCHMIT \\ Instituto Ravignani (Universidad de Buenos Aires), CONICET y \\ Universidad Nacional de General Sarmiento, Argentina
}

\section{RESUMEN}

En este artículo evaluamos el crecimiento económico y medimos los cambios en la distribución de la riqueza en una provincia argentina durante la segunda mitad del siglo XIX. Paradójicamente, en un contexto nacional de rápido desarrollo agrario, el mismo fue aquí más difícil y lento. Postulamos que tanto ese crecimiento errático como el mantenimiento de rasgos de fuerte heterogeneidad en la distribución de la riqueza se vieron afectados por procesos económicos e institucionales complejos, que incluyeron avances sobre las fronteras internas, distintas aptitudes bióticas en cada área y diferente antigüedad en la ocupación de las mismas. Analizamos, además, patrones espaciales y productivos de la riqueza, mostrando que si bien a nivel personal no varió sustancialmente, se observa un reforzamiento de los deciles medios en detrimento sobre todo de los más opulentos.

PALABRAS CLAVE: Riqueza, Distribución, Economía rural, Crecimiento económico, Argentina

Códigos JEL: D31, N36, O18

\section{ABSTRACT}

This article deals with the economic growth and the wealth-distribution changes of an Argentine province during the second half of the 19th century. This case is particularly relevant since the fast agrarian development that characterised most Argentine provinces during that period was, by contrast, much more difficult and slower there. That poor progress, as well as a persisting stronglyunequal wealth distribution, is explained by complex economic and institutional processes, closely related to changing internal boundaries, such as how new territories were exploited according to their environmental conditions and to their age as new settlements. Even though personal revenue was not radically altered, medium proprietors, however, expanded through the period his share on total wealth against more affluent groups.

KEY WORDS: Wealth, Distribution, Rural economy, Economic growth, Argentina

JEL Codes: D31, N36, O18 


\section{Introducción ${ }^{1}$}

E ste trabajo examina los cambios económicos ocurridos en la provincia de Entre Ríos, en la segunda mitad del siglo XIX, en relación con la evolución de los patrones de crecimiento económico y de la desigualdad de la riqueza rural. Sin duda este tema está asociado a un tópico central de los estudios económicos, como es la vinculación existente entre crecimiento económico y niveles de equidad o de desigualdad en la distribución de la riqueza, problema significativo que nos lleva a indagar cuáles pueden ser los factores que inciden en una mayor heterogeneidad $\mathrm{u}$ homogeneidad en el reparto de la misma.

Uno de los debates más importantes en la América del Sur actual se refiere, más que a los patrones del crecimiento económico, a las pautas y características de la distribución de la riqueza. Más allá de la existencia de erráticas tasas de crecimiento que, en lapsos muy breves, pueden pasar de ser muy altas a ser muy bajas o incluso negativas, una de las constantes más tenaces y repetidas atañe a la persistencia de altos índices de desigualdad en nuestras sociedades. Tales desigualdades pueden observarse desde múltiples ángulos, por ejemplo, al examinar las grandes tendencias en las distancias macro de los promedios de riqueza e ingreso per capita, muy evidentes ya en una comparación general entre continentes y naciones; pero también a través de una mirada más micro entre regiones, al interior de las provincias o estados que forman una nación, y aún entre grupos y personas, lo cual seguramente puede ofrecernos otras pistas sobre sus derroteros de corto plazo y sus causales, quizá incluso más firmes, o en todo caso alternativas, a las grandes miradas macro.

David Landes (1998) ha postulado que, al menos desde el siglo XVIII, se fue incrementando la tendencia a la desigualdad económica, ya se tratara de mediciones entre naciones, ya entre regiones o grupos. De modo que los interrogantes continúan llevándonos a viejas preguntas, pero muy actuales, acerca de cómo actuaron y actúan los factores económicos sobre los espacios y los diferentes actores sociales.

Hace ya muchos años se planteó una respuesta global a esos interrogantes. La misma vino de la mano de los estudios de Simon Kuznets (1966) quien, partiendo de casos de desarrollo de las principales economías capitalistas del Atlántico norte, postuló que el desarrollo económico provocaba inicialmente disparidad en la acumulación de riqueza, fruto de sectores más dinámicos que concentraban las ganancias y acumulaban capital con mayor rapidez que los restantes sectores de la economía, que quedaban de ese modo rezagados. Pero en ese esquema explicativo aquella desigual-

[Fecha de recepción del original, julio de 2007. Versión definitiva, enero de 2008]

Agradecemos sus sugerencias a los evaluadores anónimos de Investigaciones de Historia Económica. 
dad inicial tendía, en un segundo momento, a revertirse en favor de una mayor equidad, provocando en el largo plazo un nuevo equilibrio expresado en la famosa curva en forma de "U invertida" de Kuznets. Esa propuesta ha recibido múltiples críticas en las últimas décadas, tanto por la relación algo mecánica que establece entre concentración de riqueza y desigualdad, como en cuanto a los factores que explican el crecimiento de la desigualdad o de la equidad ${ }^{2}$. De manera que con los nuevos estudios se abre un interesante conjunto de interrogantes, tanto para discutir la relación o correlación existente entre crecimiento económico y desigualdad, como para analizar los factores que operan sobre la inequidad en el reparto de la riqueza ${ }^{3}$.

Intentaremos analizar aquí, para la Argentina del siglo XIX, las relaciones existentes entre la naturaleza del crecimiento económico rural, el reparto de la riqueza, la transformación institucional y las características demográficas, pues resulta significativo preguntarse sobre las formas distintivas que operaron aquellos procesos en la evolución de territorios de frontera abierta con disponibilidad de nuevos recursos (tierra, aguas, pastos), con cambiantes ciclos de migración y poblamiento (ocupación del territorio y movimientos de inmigrantes) y con transformaciones institucionales sustanciales (establecimiento de derechos de propiedad burgueses y las políticas fiscales y monetarias consiguientes); factores todos que influyeron en el desempeño de la economía decimonónica ${ }^{4}$.

La economía argentina experimentó un notable cambio socioeconómico que comenzó a visualizarse desde mediados del siglo XIX, registrando, unas décadas después, un crecimiento sostenido que, entre 1880 y 1916, llevó al país a figurar entre los más destacados de la época. Para dimensionar las trasformaciones de ese período es relevante tomar en cuenta que, en el mismo, mientras la población del país se triplicaba, la economía crecía nueve veces. Argentina llegó a registrar por entonces un producto per capita algo mayor que el de los Estados Unidos, y mucho más elevado que los correspondientes a Gran Bretaña y Francia 5 .

El factor clave de ese crecimiento económico eran las exportaciones de productos de origen agrario, entre las cuales destacaron inicialmente las lanas y los derivados del vacuno (cueros, carne salada, etc.), para más tarde agregarse los cereales y las carnes congeladas y, posteriormente, enfriadas. Todo lo cual llevó a una progresiva diversificación del abanico de bienes exportables y de los mercados a los cuales los

$2 \quad$ Atkinson (1975), Williamson y Lindert (1980), y Williamson (2002).

3 Ejemplos sobre estas cuestiones en Frank (2005), Gudmundson (1983), Johnson (1994), y Gelman y Santilli (2006).

$4 \quad$ Barsky y Gelman (2001), y Barsky y Djenderedjian (2003). Estudios recientes muestran la gran complejidad de formas de acceso a la tierra que tuvieron los productores rurales. Ver, por ejemplo, el dossier compilado por Banzato, Blanco, Blanco y Ferreyra (2007).

5 Chiaramonte (1970), Díaz Alejandro (1975), Cortés Conde (1979) y Sábato (1989). 
mismos se dirigían, así como a un gran aumento en el volumen y el valor de las exportaciones, que entre 1880 y 1914 crecieron a la par de la economía ${ }^{6}$. Buena parte de esas producciones se desarrolló especialmente en una vasta área de frontera rural en expansión que abarcaba, fundamentalmente, gran parte de las provincias de Buenos Aires, Santa Fe, Entre Ríos, Córdoba y La Pampa. Sobre esos territorios se extendió un complejo proceso de transformación productiva, con renovadas fases de poblamiento y puesta en producción de tierras, antes de frontera, orientado a proveer de manera crecientemente competitiva bienes para las nuevas demandas de productos por parte del mercado mundial. En ese contexto, las estancias, o explotaciones ganaderas, y las colonias agrícolas fueron los núcleos productivos que usufructuaron el arribo de importantes contingentes de inmigrantes europeos, beneficiándose además del creciente financiamiento bancario y del trazado de nuevas vías de circulación y comercio, mediante la construcción de una red de caminos y líneas ferroviarias.

\section{La provincia de Entre Ríos en el contexto rioplatense}

Dentro del ámbito rioplatense, Entre Ríos resulta un caso paradigmático: se trata, en primer lugar, de un área de muy tardía ocupación, situada sin embargo en una inmejorable posición geográfica para entrar en contacto con el mercado mundial. En segundo lugar, desde el último cuarto del siglo XVIII ocurrió allí una fuerte expansión de la ganadería, centrada en grandes estancias, en las que mediante pautas de producción muy extensivas, la conformación de planteles de esclavos y una especialización en torno a ciertos rubros de punta, se compensaron los factores adversos como la escasez y carestía del trabajo. En buena parte de esas unidades productivas se incorporaron, asimismo, las pautas más avanzadas de gestión de la época ${ }^{7}$.

En tercer lugar, en la primera mitad del siglo XIX aquella incipiente riqueza ganadera fue destruida y vuelta a crear en el curso de las guerras de independencia, y luego civiles, que ensangrentaron la región, teniendo un campo de batalla privilegiado en el territorio entrerriano. En ese contexto, los productores intentaron continuar generando negocios en medio del caos, logrando un notable éxito, patente sobre todo desde las décadas de 1830 y 1840 . Un éxito tanto más sorprendente cuanto que el gran problema de esa economía, la escasez de mano de obra y capital, se vio incluso aumentado con el fin de la esclavitud y el reclutamiento de buena parte de los varones para servir en los ejércitos en marcha. Esta situación fue resuelta 
mediante la acentuación del uso de técnicas muy extensivas de manejo del ganado, que compensaban la escasez de unos factores con la abundancia de otros; y, sobre todo, con un cuidadoso y complejo sistema de disposición de la mano de obra, la cual fue disciplinada por el Estado a través del esfuerzo de guerra, haciéndola partícipe al mismo tiempo de un ethos colectivo mediante el cual, de un lado, se afirmaba un vigoroso sentimiento de pertenencia a la "comunidad" de los habitantes de la provincia, y, de otro, se distribuían premios y castigos por la participación en el conflicto bélico - los primeros, en especial, dosificando los permisos para acudir a la labor rural y otorgando autorizaciones para disponer del usufructo de parcelas de tierra a los soldados meritorios ${ }^{8}$ - . De esta forma, durante esas décadas convulsas la prosperidad no estuvo precisamente ausente de la economía entrerriana; hacia 1850 ésta ya poseía la suficiente solidez como para pretender un lugar de privilegio en la constelación rioplatense, cediendo el primero sólo a Buenos Aires.

Sin embargo, las peculiares características que le habían permitido crecer parecen también haber estado luego entre los escollos que retrasaron la puesta a punto de esa economía a los dictados de la nueva época que se abrió a partir de mediados del siglo XIX. Más aún, a pesar de los fuertes cambios de la primera mitad de la centuria, no es seguro que los frutos de toda esa creación de riqueza se hayan repartido en forma equitativa, o al menos no parecen haber cambiado demasiado una situación de importante inequidad ya presente en las últimas décadas del dominio colonial. En 1808-1809, la distribución del rebaño vacuno, el elemento de riqueza más significativo, con gran diferencia, parece haber sido mucho más desigual aquí que en las otras regiones del área pampeana cercana. Las explotaciones entrerrianas eran en promedio, además, mucho más grandes ${ }^{9}$.

Pero la segunda mitad del siglo XIX fue para Entre Ríos una época de grandes transformaciones socioeconómicas e institucionales:

a) Se produjeron fuertes cambios en los patrones institucionales y jurídicos de propiedad de la tierra. Desde 1861 entró en vigencia una nueva ley de tierras, que estipuló las primeras bases jurídicas positivas para obtener su propiedad, organizándose posteriormente el catastro provincial y lográndose de esta forma consolidar y garantizar los títulos y derechos de los propietarios. Asimismo, se logró conocer por fin la magnitud de las tierras públicas, ordenándose la normativa para su disposición. Las mismas fueron luego puestas en arrendamiento o en venta durante estos decenios, quebrándose de hecho la antigua tradición de que la misma sirviera como recompensa a los servicios al Estado bajo la forma de otorgamiento de permisos de poblamiento y usufructo.

Schmit (2004).

Djenderedjian (2004). 


\section{MAPA 1}

LA PROVINCIA DE ENTRE RÍOS Y SU DIVISIÓN POLÍTICA HACIA 1892*

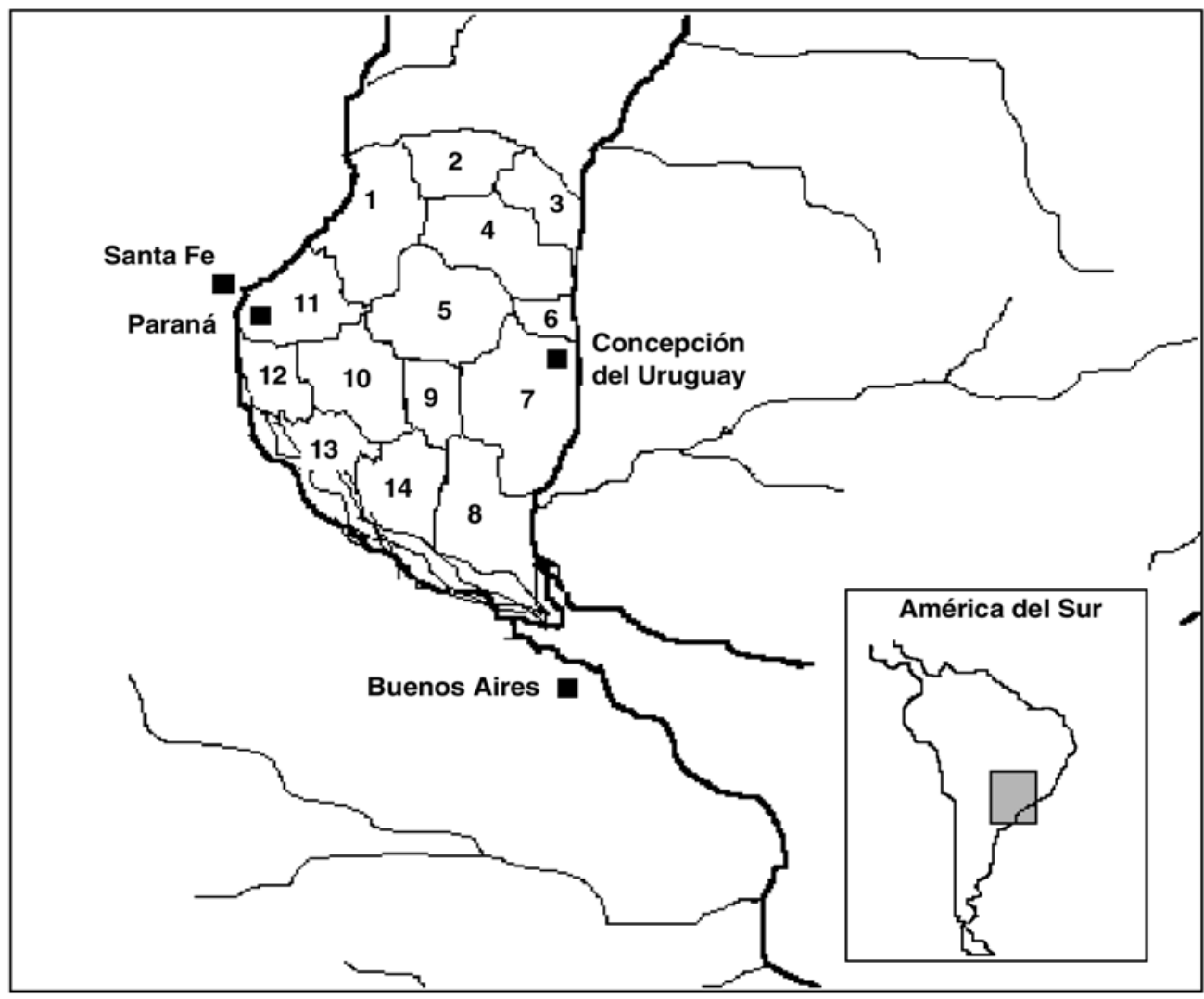

Leyenda: (1) La Paz, (2) Feliciano, (3) Federación, (4) Concordia, (5) Villaguay, (6) Colón, (7) Uruguay, (8) Gualeguaychú, (9) Tala, (10) Nogoyá, (11) Paraná, (12) Diamante, (13) Victoria y (14) Gualeguay.

(*) Hemos preferido presentar el mapa con la división política de 1892, dado que la mayor parte de los datos se encuentran detallados por departamentos y no por zonas. Los departamentos de Feliciano y Federación fueron creados en 1883, detrayendo superficies de los de La Paz y Concordia, respectivamente.

Fuentes: Elaboración propia a partir de Felquer y Moreira Bahler de Felquer (1962), e/pp. 130-131.

b) Se experimentó el paso de una estructura productiva ganadera muy extensiva, centrada en torno a la explotación del vacuno alzado (no sometido a rodeo), a otra basada en una producción ganadera vacuna y ovina de rodeo que, posteriormente, comenzaría con bastante timidez a incorporar mejoras genéticas. Acaeció asimismo una significativa expansión de la producción de los saladeros, manufacturas que posibilitaban un aprovechamiento más intensivo del ganado, ya que de él se comenzaron a obtener no sólo cueros curtidos, sino también 
carne salada, ceniza que servía como abono, huesos, sebo, aceite y otros diversos productos. Los saladeros aumentaron en dimensión y en niveles de inversión, tornándose en empresas que empleaban a cientos de trabajadores ${ }^{10}$. Todo ello implicó una presión acrecentada sobre la mano de obra.

c) Se intensificó la ocupación en las tierras de la frontera rural, sobre todo en el interior provincial, área cubierta todavía por densos matorrales que, en buena parte, poseía peores características agro-ecológicas que muchas zonas de antigua ocupación. Es de destacar, en todo caso, la inexistencia de una frontera indígena, por lo que el proceso de ocupación de esas nuevas tierras, de carácter incruento, abarcó a la vez un arco de tiempo más extenso y fue pautado por ritmos de intensidad desiguales.

d) La expansión demográfica alcanzó su punto más alto, con una tasa anual de crecimiento aproximada del 4,2 por 100, entre 1856 y 1869. Así, la población de la provincia pasó de 79.284 a 134.271 habitantes ${ }^{11}$. Sin embargo, entre el último año citado y mediados de la década de 1890, la expansión parece haber sido menor: hacia 1883, un nuevo censo provincial situaba el número de habitantes en 204.000, cifra que implicaba una tasa anual de crecimiento de alrededor del 3 por 100 desde 1869, que se mantuvo hasta 1895, en que el censo nacional arrojó para la provincia la cifra de 295.379 habitantes $^{12}$. Es de destacar, sin embargo, que la población rural creció con mayor rapidez que la total, pasando entre 1869 y 1895 de 78.891 a 194.141 habitantes, esto es, a una tasa de más del 3,5 por 100 anual.

e) La proporción de extranjeros aumentó también sustancialmente debido a la puesta en marcha de las primeras experiencias de colonización agrícola ${ }^{13}$. Pero las resistencias ofrecidas por parte de la población rural criolla, así como la emergencia de severos conflictos políticos entre los grupos dominantes, llevaron a una cruenta rebelión a inicios de la década de 1870, que tuvo un alto costo económico y que significó un impasse en el desarrollo del fenómeno de la colonización hasta la segunda mitad de esa década. Ello originó un retraso relativo con

10 Macchi (1971)

11 Censo de 1856 en Hudson (1867), pp. 115 y ss. Los datos de 1869 en De la Fuente (1872). En buena parte, ese crecimiento se debió a la incorporación de inmigrantes provenientes de otras provincias o del exterior. Vázquez de la Morena (1886), p. 627; De la Fuente, Carrasco y Martínez (1898), t. II.

Durante la segunda mitad del siglo XIX, la agricultura se expandió fuertemente en Argentina a través de la fundación de colonias agrícolas, es decir, núcleos creados y organizados por lo general en tierras de uso ganadero o aún no ocupadas, que eran poblados a través del ofrecimiento en venta a plazos de las parcelas resultantes de la subdivisión del terreno. A menudo estas colonias se formaban con inmigrantes europeos, pero la presencia de población criolla llegó a ser importante. Por contrato, las familias pobladoras debían dedicar una proporción sustancial de la superficie de sus parcelas a la agricultura, para lo cual existía una administración que ofrecía asesoramiento, maquinaria agrícola, semillas e incluso créditos. Un libro clásico al respecto es el de Gallo (1983). 
respecto a otras experiencias más exitosas, pues entre 1870 y 1879 se fundaron en Entre Ríos sólo 14 colonias; mientras que en Santa Fe, en el mismo período, se organizaron nada menos que $41^{14}$. Si bien luego el proceso se aceleró, nunca llegó a alcanzar la tasa de crecimiento santafesina. De esta forma se explica que, para 1895, los cultivos sólo cubrieran 430.596 hectáreas, el 5 por 100 de la superficie provincial, frente a 1.684 .937 en Santa Fe, el 13 por 100 de su territorio.

f) Finalmente, se intentó instalar nuevos medios de circulación, iniciándose la construcción de ferrocarriles. Sin embargo, por varias décadas más el tráfico fluvial continuó organizando prioritariamente el traslado de bienes y personas, favoreciendo la continuidad de la importancia de las zonas costeras en detrimento de las interiores. La provincia, excelentemente dotada de vías fluviales, apostó durante décadas por ellas debido a sus ventajas comparativas con respecto a los fletes por tierra mediante tracción a sangre, más lentos y caros; pero una vez que, hacia la década de 1870, los ferrocarriles cambiaron la ecuación de costos en favor del transporte terrestre, Entre Ríos se encontró con que diversos obstáculos de orden natural, como la abundante presencia de cursos de agua, una alta humedad relativa $y$, a veces, fuertes desniveles del terreno, volvían su construcción más costosa. Así, no sorprende que el desarrollo del ferrocarril fuera bastante tardío, marginal y complicado en la provincia, donde su rentabilidad nunca alcanzó cotas comparables a las logradas en otras. Hacia 1876, de los 2.287 kilómetros de líneas ferroviarias en servicio o en construcción en toda la Argentina, sólo 164 correspondían a Entre Ríos, mucho menos que a cualquier otra provincia de su magnitud ${ }^{15}$. El retraso posteriormente se afianzó; si en 1876 Entre Ríos poseía más del 7 por 100 del total de la longitud de las líneas férreas del país, en 1895, con 717,8 kilómetros sobre 14.799, su participación proporcional había bajado a menos del 5 por $100^{16}$.

\section{La evolución de la riqueza comparada de las provincias argentinas integrantes del área pampeana entre 1860 y 1892}

Como hemos dicho, la riqueza ganadera entrerriana de mediados del siglo XIX no tenía parangón entre las provincias rioplatenses, siendo sólo superada por la de Buenos Aires. Todavía al promediar la segunda mitad de dicho siglo alcanzaba 2.500.000

Raña (1904) y Fernández (1896).

Napp (1876), pp. 316-317.

De la Fuente, Carrasco y Martínez (1898), t. III, pp. cliv; 469. 
cabezas de ganado vacuno, 1.000.000 de equino y 3.000.000 de lanar, sin duda menos que la de Buenos Aires, pero más de los que poseía cualquier otra provincia ${ }^{17}$. El crecimiento, sin embargo, no fue uniforme. Entre 1864 y 1884, la cabaña ovina entrerriana creció más de un 120 por 100, pasando de 1.550.000 animales a 3.415.000; en cambio, el vacuno sólo aumentó alrededor de un 8 por $100^{18}$. Más significativo aún, el valor medio de las cabezas de ganado era menor que el registrado en las provincias más dinámicas, en especial en el caso de los lanares, valorados en 1875, según datos oficiales, a precios un 33 por 100 menores que los correspondientes a los rebaños mestizados bonaerenses ${ }^{19}$. Esto muestra la complejidad experimentada en Entre Ríos por el proceso de mestizaje ovino, así como por la menor calidad general del ambiente para esa producción, que sufría mucho con la alta humedad relativa y los duros pastos de la provincia; sólo el área del sur, en el departamento de Gualeguay, podía ser considerada óptima al respecto. Es por ello que, tan tarde como en 1886, las lanas entrerrianas tenían todavía un rendimiento neto de 35 a 38 por 100 después del lavado, es decir, menos que las bonaerenses, que alcanzaban de un 37 a 41 por $100^{20}$.

La década de 1880 fue, como para otras provincias, una época de rápido desarrollo económico. Siempre a la zaga de la potencia santafesina, en Entre Ríos se afianzó en estos años el proceso colonizador, se amplió la infraestructura de transportes y progresó el cambio del patrón productivo ganadero hacia pautas más modernas. Pero de todos modos la peculiar ecuación de factores de la provincia parece haber marcado un freno a esa expansión: un indicio al respecto lo tenemos en que la superficie promedio de las colonias fundadas en ese período fue mucho menor que la de otras provincias. Algo muy llamativo sobre todo en comparación con provincias que habían avanzado recientemente sobre sus fronteras indígenas, como Córdoba y Santa Fe, disponiendo por tanto de la posibilidad de ofertar esas tierras a valores más bajos de lo que era posible conseguir por entonces en Entre Ríos.

Pero, además, puede intuirse ese proceso en las alternativas mismas sufridas por el fenómeno de la colonización. Como hemos dicho ya, la progresión fue bastante disímil: según los datos recopilados en el censo de 1895, Entre Ríos, pese al retraso de la década de 1870, no sólo no logró nunca alcanzar el ritmo de crecimiento de su vecina Santa Fe, sino que, además, su promedio de hectáreas por colonia, que ya en el lapso 1871-1880 era más bajo aún que el de Córdoba, descendió en la década siguiente a unas irrisorias 465 hectáreas, lo que marca entre otras cosas los límites que el proceso de valorización de la tierra había ido imponiendo al fenómeno (Cuadro 1).

\footnotetext{
Napp (1876), p. 311.

Mulhall y Mulhall (1885), p. 556.

Napp (1876), p. 311.

Huergo (1887), p. 237; Argentina, Provincia de Entre Ríos (1888), p. 16.
} 
CUADRO 1

CANTIDAD Y SUPERFICIE DE COLONIAS FUNDADAS EN SANTA FE, CÓRDOBA Y ENTRE RÍOS

\begin{tabular}{lrrrrrr}
\hline & \multicolumn{3}{c}{$\mathbf{1 8 7 1 - 1 8 8 0}$} & & & $\mathbf{1 8 7 1 - 1 8 8 0}$ \\
\hline & Colonias & $\begin{array}{c}\text { Hectáreas } \\
\text { colonizadas }\end{array}$ & Promedio & Colonias & $\begin{array}{c}\text { Hectáreas } \\
\text { colonizadas }\end{array}$ & Promedio \\
\hline Santa Fe & 39 & 431.240 & 11.057 & 181 & 1.877 .734 & 10.374 \\
Córdoba & 4 & 36.549 & 9.137 & 53 & 580.422 & 10.951 \\
Entre Ríos & 27 & 206.536 & 7.649 & 119 & 55.279 & 465 \\
\hline
\end{tabular}

Fuentes: Elaboración propia a partir de De la Fuente, Carrasco y Martínez (1898), t. I, pp. 652 y ss.

Pero no sólo se trataba de que las colonias fueran menos extensas. Karl Kaerger efectuaba en 1897 algunas agudas consideraciones al respecto, cuando afirmaba que una de las diferencias fundamentales entre la colonización santafesina o cordobesa y la entrerriana era que, en esta última, no había tenido lugar la colonización "preparatoria", que consistía en establecer arrendatarios o medianeros en tierras de estancia con contratos que duraran de tres a cinco años y con la obligación de sembrar alfalfa luego del último trigo. Aunque esta circunstancia contribuía a hacer descender el precio de la tierra - dado que, a cambio de encontrar gente que aceptara esos contratos, los estancieros estaban dispuestos a ofrecerles el arrendamiento a mucho menor costo y en condiciones más favorables-, a los ganaderos entrerrianos no les resultaba útil sembrar alfalfa puesto que al cabo de algunos años ésta se perdía. Así, la primera consecuencia de ello era que la tierra se cedía en condiciones más gravosas; y la segunda, que no existían grandes extensiones disponibles para el arriendo, redundando en límites a la capacidad de los agricultores para ampliar su escala productiva o, incluso, para acumular capital e independizarse ${ }^{21}$. De esta forma, los colonos trataban de arrendar o comprar tierras cercanas a las que ya poseían, lo cual presionaba sobre la demanda en las áreas proporcionalmente más colonizadas o más ricas, aumentando aún más los precios.

En lo que respecta a la ganadería, aunque hacia 1895 los avances del mestizaje habían sido concretos, todavía resultaban demasiado exiguos, sobre todo en comparación con las demás provincias. Mientras que en Buenos Aires la proporción de

21 Kaerger (2004 [1897]), pp. 434-436. Bavio et al. (1893), participando de los lugares comunes que se comenzaban a gestar en la época, desaprobaba el arrendamiento como forma de colonización, sin ver las posibilidades del mismo. 
ganado bovino mestizo y puro sobre el total oscilaba en torno al 50 por 100, en Entre Ríos apenas arañaba el 17 por 100, cifra que resulta todavía más llamativa en el contexto del descenso del stock que se infiere de las cifras de los censos de 1888 y 1895, descenso que no se verifica en las demás provincias ${ }^{22}$. Si bien en cuanto al ovino las cifras son mucho más alentadoras (se pasó de 4.901 .123 cabezas en 1888 a 6.210 .185 en 1895, aumentando la proporción de puros y mestizos del 9 al 70 por 100), es menester recordar que hacia la última década del siglo XIX este rubro había dejado de estar entre los más dinámicos, siendo reemplazado por el vacuno, ahora ligado al aprovechamiento más intensivo que entrañaba la venta al exterior en pie y la producción de carnes congeladas y enfriadas en los frigoríficos.

Y es también un indicio de tales dificultades la permanencia del peso de la ganadería en la economía provincial. Hacia 1884, los hermanos Mulhall calculaban el ingreso entrerriano en 21.380.000 de pesos oro; de éste, los productos pecuarios suponían casi el 50 por 100. Por el contrario, en Santa Fe éstos sólo daban cuenta de menos del 24 por 100, frente al casi 40 por 100 provisto por las actividades agrícolas; incluso en Buenos Aires, la actividad ganadera representaba sólo un 30 por 100 del ingreso, ocupando el comercio, la banca, los servicios y la manufactura un 42 por 100. En 1884, el área cultivada en Entre Ríos apenas llegaba a 125.000 acres, siendo en Santa Fe diez veces mayor ${ }^{23}$. La comparación de los datos de 1884 y 1892 que manejaban estos autores indica que ese alto peso de la ganadería en la economía provincial sólo se había modificado parcialmente en la última fecha: de un ingreso anual total calculado en 42 millones de pesos oro, la producción ganadera daba cuenta de 16.800.000, alrededor del 40 por 100 del total. La agricultura, cuya expansión en la década anterior había sido muy rápida, apenas significaba, sin embargo, 5.700.000 pesos oro, el 14 por 100 del total ${ }^{24}$.

De manera que la posición entrerriana entre las provincias argentinas acusaba también los límites de los cambios de la dorada década de 1880. Su situación relativa en cuanto a riqueza per cápita entre 1884 y 1892 también había descendido, pasando del segundo al tercer lugar en relación con las demás provincias. Si bien la economía entrerriana parece haber resultado menos afectada por la dura crisis de 1890,

22 El rebaño bovino total entrerriano pasó de 3.927.213 a 2.519.416 cabezas. Barsky y Djenderedjian (2003), p. 429.

23 Mulhall y Mulhall (1885), pp. 33, 268 y 409. Los Mulhall basaron sus estimaciones en datos censales y registros estadísticos oficiales, sobre todo los publicados en 1881 para Buenos Aires, y 1882-1884 para Entre Ríos y Santa Fe, además de varias obras descriptivas e informes sobre deuda pública, presupuestos nacionales y bancos, agregando información recogida por sus propios medios. Si bien estas estimaciones pueden ser objeto de crítica, ambos hermanos, y sobre todo Michael, fueron en su tiempo respetados estadígrafos a nivel mundial. Ver, al respecto, Da Silva (1965). 


\section{CUADRO 2}

VALOR DE LA RIQUEZA EN LAS PROVINCIAS ARGENTINAS POR RUBRO, 1892

(en millones de pesos oro)

\begin{tabular}{lrrrrrrr}
\hline & Tierra & Ganado & Casas & FF.CC. & $\begin{array}{c}\text { Artículos } \\
\text { diversos }\end{array}$ & Total & $\begin{array}{c}\text { Per cápita } \\
\text { (dólares oro) }\end{array}$ \\
\hline Buenos Aires & 341 & 135 & 333 & 190 & 333 & 1.332 & 950 \\
Santa Fe & 45 & 23 & 28 & 45 & 47 & 188 & 740 \\
Entre Ríos & 70 & 38 & 27 & 13 & 49 & 197 & 660 \\
Córdoba & 40 & 20 & 29 & 55 & 48 & 192 & 505 \\
Catamarca & 10 & 3 & 9 & 8 & 10 & 40 & 320 \\
Corrientes & 28 & 15 & 21 & 8 & 24 & 96 & 330 \\
Jujuy & 4 & 1 & 4 & 2 & 4 & 15 & 170 \\
La Rioja & 6 & 2 & 6 & 4 & 6 & 4 & 240 \\
Mendoza & 26 & 2 & 11 & 13 & 17 & 69 & 420 \\
Salta & 14 & 3 & 12 & 8 & 12 & 49 & 250 \\
San Juan & 26 & 2 & 8 & 4 & 13 & 53 & 420 \\
San Luis & 10 & 4 & 6 & 8 & 9 & 37 & 370 \\
Santiago & 9 & 6 & 12 & 15 & 14 & 56 & 350 \\
Tucumán & 17 & 3 & 14 & 9 & 16 & 59 & 280 \\
\hline TOTAL & 646 & $\mathbf{2 5 7}$ & $\mathbf{5 2 0}$ & $\mathbf{3 8 2}$ & $\mathbf{6 0 2}$ & $\mathbf{2 . 4 0 7}$ & \\
\hline
\end{tabular}

Fuente: Mulhall y Mulhall (1892), p. 22.

el mismo hecho de que el descenso posterior del precio de la tierra haya sido menos acentuado que en las demás revela que ese factor continuaba siendo una clave importante en las rigideces que, sin duda, constreñían el desarrollo provincial (Cuadro 2).

En efecto, según estos cálculos la provincia pampeana en la que la tierra parece haber aumentado más intensamente su valorización fue Entre Ríos ${ }^{25}$. Esto contrasta fuertemente con lo ocurrido en Buenos Aires, donde el desarrollo y catastrófico final del ciclo especulativo desatado entre 1886 y 1890 había provocado que, en 1892, el valor de la tierra sólo hubiera aumentado, desde 1884, a poco más del 1,5 por 100 anual acumulativo. $\mathrm{O}$ el caso de Santa Fe, donde, en el mismo período, el valor de la tierra se estancó. Por el contrario, en Entre Ríos el aumento fue de más del 7,5 por

25 Pasando de 39 a 70 millones de pesos oro entre 1884 y 1892, sólo superada en todo el país por la pequeña provincia de San Juan. 
100 anual, lo cual nos estaría indicando que los factores que presionaban desde hacía mucho tiempo en el sentido de una mayor valorización de la tierra, continuaron e, incluso, incrementaron su actuación a lo largo del período.

\section{La evolución y distribución de la riqueza rural entrerriana entre 1874 y 1892}

Como hemos dicho, en este estudio presentaremos un análisis comparativo de datos de distribución de riqueza inmobiliaria rural entre 1874 y 1892. Dado que no contamos con registros catastrales ordenados y completos ${ }^{26}$, optamos por efectuar mediciones de la superficie poseída por cada propietario según aparece en los mapas topográficos de ambos años ${ }^{27}$. Si bien el nivel de detalle de esos mapas es notable, existen varios casos en que los nombres de los dueños no se especifican, o en los que no es posible deducir la posesión de diversas tenencias en cabeza de un mismo propietario. Esto es principalmente visible en lo que respecta a las colonias agrícolas, de las cuales sólo se consigna la división de los lotes. Sabemos por diversas fuentes que fenómenos como la multipropiedad de diversas parcelas, el arrendamiento durante períodos de diversa extensión, o combinaciones de propiedad y arrendamiento, eran muy frecuentes en las mismas. Igualmente, existe el problema de evaluar los muy diversos grados de cancelación de las deudas hipotecarias hasta la obtención de la plena propiedad, tarea hoy irrealizable por la falta de registros contables de todas las diversas empresas involucradas. Por lo demás, las diferencias en la dotación no sólo estribaban en la cantidad de hectáreas poseídas, sino también en el muy desigual valor de las mismas según fuera la posición geográfica de la colonia, la situación respecto de las vías de comunicación, la calidad de las tierras, las facilidades de venta ofrecidas por el propietario, la cercanía de otras colonias más antiguas (lo que aumentaba considerablemente la demanda en función de las necesidades expansivas de agricultores enriquecidos) y otros múltiples factores. De este modo, más allá de que con cierto trabajo sería posible reconstruir los datos de algunas colonias en particular, resulta hoy imposible conocer los de todas en el momento puntual de confección de cada mapa catastral. Esto impidió medir con rigor el impacto directo del proceso de colonización en el reparto de la tierra. Si bien ello constituye una considerable limitación, la exclusión de las colonias nos permitirá trabajar con un univer-

\footnotetext{
26 El archivo correspondiente fue en parte incinerado y el resto es inaccesible, aún cuando se conservan diversos expedientes sin clasificar en el Archivo Histórico y Administrativo de Entre Ríos. 
so más homogéneo, en tanto se circunscribirá a las tierras que se habían visto menos afectadas por ese proceso en el período objeto de estudio.

Como se ha dicho anteriormente, los años que transcurren entre 1874 y 1892 estuvieron marcados sin duda por la expansión del fenómeno colonizador: si en el primero de esos años sólo existían siete colonias, en el segundo había ya alrededor de $300^{28}$. Pero debe también recordarse que muchas de esas colonias (o, al menos, algunas de las más extensas) habían sido erigidas en los ejidos de los pueblos, en cumplimiento de la ley de 1872 que reservaba los mismos a usos agrícolas. Éstos no fueron incluidos en la medición de la riqueza rural de 1874, por lo que su colonización agrícola en 1892 no distorsiona las cifras obtenidas. Por otra parte, la superficie total colonizada hacia 1892 apenas ascendía, según diversas fuentes, a una extensión que oscilaba entre 752.000 y 890.000 hectáreas, alrededor del 10 por 100 de la superficie provincial, de las cuales sólo se hallaba cultivada la mitad ${ }^{29}$. De esta forma, no puede decirse que el anclaje del fenómeno colonizador hacia ese último año haya constituido un hecho que transformara radicalmente la tenencia de la tierra y la creación de riqueza en el territorio provincial.

Los mapas catastrales nos ofrecen, por tanto, una visión general pero limitada de la distribución de la riqueza inmobiliaria rural, ya que probablemente dejan fuera una proporción significativa de unidades productivas pequeñas y de familias desposeídas, así como un notable universo de arrendatarios. Pero tienen la ventaja de ofrecer datos homogéneos y comparables, que abarcan a toda la provincia, con lo cual constituye, por ahora, la única forma en que podemos conocer con algo más de detalle las muy fuertes diferencias regionales y su evolución en esas décadas cruciales. Hemos calculado las superficies individuales que figuran allí para cada propiedad, confrontándolas, cuando fue posible, con los datos que surgen de otros registros (testamentarias, escrituras y fuentes secundarias) para verificarlas. Obtenidas las superficies, y a fin de reflejar las muy distintas situaciones ambientales y espaciales de cada parcela (notables en ambas épocas), las mismas fueron valorizadas.

Para los registros de 1874 se utilizaron las evaluaciones fiscales en pesos bolivianos del 1877, vigentes en las leyes que regulaban la venta de las tierras públicas, y que se encuentran en el registro oficial ${ }^{30}$. Las tierras fueron divididas en cinco cla-

28 Si bien el censo de 1895 sólo registra 191 colonias, la confrontación con otras diversas fuentes amplía considerablemente esa cifra. Ver Weyne (1988), p. 33. Los datos del censo de 1895 en De la Fuente, Carrasco y Martínez (1898), t. I, pp. 652 y ss.

29 Cálculos de Kaerger (2004 [1897]), p. 444; y estimaciones a partir de los datos de Bavio et al. (1893) y Raña (1904).

30 El peso boliviano, de 20 gramos y 900 milésimos de plata feble, corrió como moneda local en Entre Ríos hasta la reforma monetaria de 1881. Su valoración osciló, de 1874 a 1879, entre 65 y 79 centavos de peso fuerte (el antiguo peso de plata español), tanto por el Banco de la Provincia de Buenos Aires, como por el Provincial de Santa Fe. Álvarez (1929), pp. 110-111 y 115-118. 
ses ("con monte y con agua"; "con monte y sin agua"; "con agua y sin monte"; "sin monte y sin agua"; "anegadizos"), segmentándose la provincia en 13 zonas con límites detallados. Esas evaluaciones fueron consideradas en la época como bastante ajustadas a la realidad, si bien, al tratarse de campos fiscales, las mismas eran, sin duda, algo inferiores a los precios de mercado de las tierras particulares ${ }^{31}$. Lo importante es, sin embargo, la proporción de los valores según la calidad de los suelos, lo cual permite diferenciar claramente el capital que representaban las grandes extensiones situadas en zonas agro-ecológicamente malas o mediocres de aquéllas que, por el contrario, estaban situadas en áreas más privilegiadas. Se obtuvo un precio medio de la hectárea para cada zona, multiplicándoselo luego por la cantidad individual poseída.

Para el registro de 1892 contamos con datos de ventas concretas de tierras en los distintos distritos de los 14 departamentos que entonces existían, procedentes de las cifras publicadas por la Dirección General de Estadística de la Nación y del Departamento General de Estadísticas de Entre Ríos. Se optó por tomar un promedio de los años 1894-1896 a fin de reflejar una situación de recuperación relativa del mercado de tierras tras la crisis de 1890 y de contar con rangos de datos más amplios ${ }^{32}$. Para volver comparables las series de ambos años, convertimos los montos de 1874 (calculados en pesos bolivianos) a pesos moneda nacional de 1892. Los resultados principales se resumen en el Cuadro 3.

Como puede verse, la riqueza inmobiliaria total de la provincia creció en el período a una tasa de alrededor del 10,8 por 100 anual, bastante más que la tasa de propietarios, que se elevó a razón del 4,77 por 100 anual. Si bien aquí cabría agregar la muy fragmentada superficie de las áreas coloniales, es también evidente que esas eran justamente las más valorizadas, lo que debería reflejarse también en el conjunto de la riqueza inmobiliaria rural; pero la exigua proporción de esas áreas colonizadas sobre el total sugiere que su peso no debió de haber sido tan significativo. En todo caso, se trata de una progresión algo mayor que el aumento de la población rural, que creció entre ambos años, como hemos dicho, al 3,5 por 100 anual. Puede verse, también, que los valores máximo, mínimo y promedio aumentaron en proporción mucho menor que el monto total, lo que muestra claramente la dimensión del proceso de fragmentación de la propiedad. En síntesis, si bien pareciera que el aumento de productividad agraria pudiera explicar una parte de esa valorización, ese aumento se encontraba limitado por el propio peso de la demanda generada por el crecimiento poblacional y el incremento en el número de propietarios. Debe tenerse presente también que el arrendamiento de tierras aumentó asimismo en este período,

$31 \quad$ Vázquez de la Morena (1886), p. 631.

32 Argentina. Dirección General de Estadística (1895), 27 y ss.; y Argentina, Provincia de Entre Ríos (1897). 


\section{CUADRO 3}

RESUMEN DE VALORES DE RIQUEZA EN TIERRAS EN ENTRE RÍOS, 1874-1892

(en pesos moneda nacional de 1895) ${ }^{33}$

\begin{tabular}{lrrr}
\hline \multicolumn{1}{c}{1874} & \multicolumn{1}{c}{$\mathbf{1 8 9 2}$} & $\begin{array}{c}\text { Diferencia } \\
\text { (en porcentaje) }\end{array}$ \\
\hline Capital total & 22.295 .952 & 142.292 .233 & 538 \\
Valor máximo & 2.953 .081 & 8.225 .010 & 179 \\
Valor mínimo & 276 & 729 & 164 \\
Promedio & 22.915 & 63.157 & 176 \\
Mediana & 8.426 & 21.849 & 159 \\
Moda & 3.452 & 16.200 & 369 \\
Casos & 973 & 2.253 & 132 \\
\hline
\end{tabular}

Fuentes: González (1874) y Nolte (1892).

aunque no podamos conocer su dimensión. Y, sobre todo, que hacia 1892 el mismo desarrollo institucional y el proceso de regularización de las tenencias fundiarias promovió, de una u otra forma, mayor seguridad jurídica y, por tanto, más razones para que los valores de la tierra pudieran acercarse a óptimos más altos que los de las dos décadas precedentes.

Dentro de los datos de 1874, el 20 por 100 de más escasos recursos involucraba a unos 195 propietarios, cada uno de los cuales poseía hasta 1.475 pesos bolivianos de capital, o 3.452 pesos moneda nacional de 1895. Todas sus tenencias concentraban el 1,76 por 100 de la riqueza fundiaria total. Un sector intermedio estaba conformado por el 60 por 100 siguiente, con 583 individuos poseedores de tierras y un promedio cada uno de algo más de 9.500 pesos moneda nacional en propiedades rurales, concentrando el 25 por 100 de todo el capital inmobiliario. De esta forma, el 80 por 100 de los propietarios, que tenía como máximo propiedades por alrededor de 21.065 pesos, alcanzaba a poseer el 27 por 100 de la riqueza en tierras. Finalmente,

33 Tanto para este cuadro, como para los siguientes, los valores de 1874 (en pesos bolivianos) fueron convertidos a pesos moneda nacional de 1892 utilizando las tablas de Álvarez (1929). Entre los 973 casos de 1874 y los 2.253 de 1892 existen varios propietarios que poseían tierras en distintos departamentos; para el análisis general de la provincia hemos agrupado sus tenencias, pero, en los cálculos que efectuaremos más adelante por departamento, hemos considerado únicamente las propiedades que poseyeran en la circunscripción de que se tratase, por lo que el número total aumenta. 


\section{GRÁFICO 1}

CURVAS DE LORENZ DE LA PROPIEDAD RURAL EN ENTRE RÍOS, 1874 Y 1892
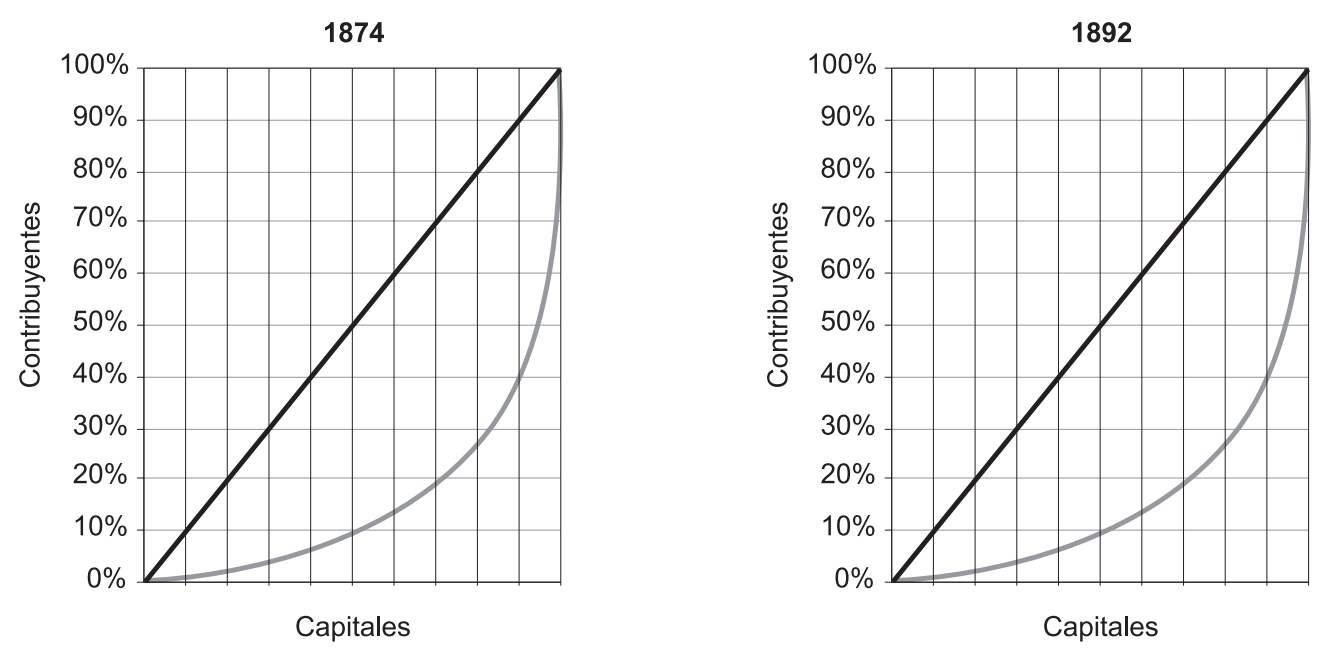

Fuentes: González (1874) y Nolte (1892).

los 195 propietarios correspondientes al 20 por 100 del estrato superior, poseían un promedio individual de 83.866 pesos, y concentraban el 73,3 por 100 del total de los capitales inmobiliarios. En la cumbre de este sector, sólo 7 personas (el 0,72 por 100 del total) acumulaban el 26,8 por 100 de la riqueza inmobiliaria, con un promedio de alrededor de 854.356 pesos cada uno. El índice de Gini es de 0,6951, y el coeficiente 20/20 de 41,57, lo que muestra, adicionalmente, la alta heterogeneidad en la distribución de la riqueza fundiaria, que también se evidencia en la correspondiente curva de Lorenz.

Para 1892 los índices se han modificado levemente, acentuándose la ya alta heterogeneidad existente en 1874. El índice de Gini es ahora de 0,700, y el coeficiente 20/20 de 43,78. Para este año, el 20 por 100 de los propietarios de menor dimensión continúa poseyendo alrededor de un 1,7 por 100 del total de la riqueza inmobiliaria, y el 20 por 100 superior alrededor del 74 por 100. Sin embargo, dentro del estrato superior, el sector más rico ha disminuido su proporción: si, para compararlos con los de 1874, consideramos al 0,72 por 100 de los terratenientes más importantes en 1892 (16 casos), veremos que ahora controlan sólo el 22 por 100 del total de los capitales inmobiliarios. 


\section{CUADRO 4}

INDICADORES DEL VALOR DE LA PROPIEDAD TERRITORIAL POR DEPARTAMENTO

Y DE SU DISTRIBUCIÓN, ENTRE RÍOS, 1874

(en pesos moneda nacional de 1895)

\begin{tabular}{lrrrrr}
\hline Departamentos & Casos & Valor máximo & Valor mínimo & Gini & $\mathbf{2 0 / 2 0}$ \\
\hline Colón & 46 & 189.587 & 758 & 0,618 & 28,02 \\
Concordia & 109 & 214.958 & 537 & 0,544 & 26,92 \\
Diamante & 48 & 59.217 & 1.184 & 0,511 & 22,50 \\
Gualeguay & 109 & 136.502 & 758 & 0,578 & 24,79 \\
Gualeguaychú & 103 & 851.970 & 655 & 0,752 & 72,15 \\
La Paz & 81 & 318.843 & 834 & 0,614 & 43,99 \\
Nogoyá & 82 & 93.623 & 936 & 0,547 & 21,07 \\
Paraná & 101 & 362.742 & 537 & 0,645 & 28,93 \\
Tala & 72 & 31.598 & 2.107 & 0,361 & 6,83 \\
Uruguay & 51 & 1.052 .206 & 6.636 & 0,707 & 44,48 \\
Victoria & 128 & 203.338 & 276 & 0,464 & 17,66 \\
Villaguay & 91 & 105.326 & 936 & 0,477 & 17,15 \\
\hline TOTAL & $\mathbf{1 . 0 2 1}$ & & & 0,695 & \\
\hline
\end{tabular}

Fuentes: González (1874) y Nolte (1892).

\section{La riqueza por departamento}

Trataremos de brindar ahora una imagen de la distribución de la riqueza entrerriana por departamentos, para lo cual compararemos los datos de 1874 y 1892. Hemos reelaborado las bases agrupando en un solo registro a quienes poseyeran diversas propiedades pero dentro del mismo departamento, y desagregándolos en los casos en que las poseían en otros. De esa forma, el total de propietarios en 1874 aumenta de 973 a 1.021, y el de 1892 pasa de 2.253 a 2.335 .

Puede verse en el Cuadro 4 que, en lo que atañe al reparto de la riqueza fundiaria en el interior de la provincia, presentan un patrón con una heterogeneidad mayor los departamentos de antigua ocupación con orientación ganadera y pautas extensivas de explotación, como por ejemplo Concepción del Uruguay o, en menor grado, Gualeguaychú. Es significativo, además, que en estos departamentos estén radicadas las fortunas más grandes y, en general, una mayor riqueza global que en los restantes. Por el contrario, aquellos departamentos con un reparto más homogéneo de la riqueza inmo- 


\section{CUADRO 5}

INDICADORES DEL VALOR DE LA PROPIEDAD TERRITORIAL POR DEPARTAMENTO

Y DE SU DISTRIBUCIÓN, ENTRE RÍOS, 1892

(en pesos moneda nacional de 1895)

\begin{tabular}{lrrrrr}
\hline Departamentos & Casos & Valor máximo & Valor mínimo & Gini & $\mathbf{2 0 / 2 0}$ \\
\hline Colón & 73 & 2.941 .110 & 9.396 & 0,668 & 38,44 \\
Concordia & 135 & 1.912 .680 & 2.916 & 0,718 & 45,91 \\
Diamante & 94 & 733.050 & 2.430 & 0,548 & 18,70 \\
Federación & 56 & 400.950 & 5.670 & 0,473 & 14,08 \\
Feliciano & 114 & 388.800 & 1.080 & 0,563 & 30,28 \\
Gualeguay & 193 & 781.650 & 929 & 0,668 & 34,41 \\
Gualeguaychú & 257 & 1.425 .600 & 729 & 0,685 & 50,42 \\
La Paz & 151 & 2.430 .000 & 1.458 & 0,697 & 44,19 \\
Nogoyá & 253 & 467.775 & 1.296 & 0,595 & 24,00 \\
Paraná & 276 & 387.450 & 2.160 & 0,563 & 21,06 \\
Tala & 217 & 115.367 & 1.162 & 0,484 & 13,77 \\
Uruguay & 84 & 5.216 .400 & 6.561 & 0,759 & 75,10 \\
Victoria & 188 & 189.000 & 855 & 0,469 & 12,50 \\
Villaguay & 244 & 610.416 & 2.104 & 0,533 & 16,21 \\
\hline TOTAL & 2.335 & & & 0,700 &
\end{tabular}

Fuentes: González (1874) y Nolte (1892).

biliaria rural parecen ser los que cuentan con mayor proporción de tierras de ocupación más reciente (en especial los del interior y el sureste, como Rosario del Tala o Diamante), ligados por otra parte en forma más intensa al reciente proceso de colonización y, por ende, con mayor presencia de agricultura y de medianos y pequeños propietarios.

Incluso todavía en 1892 parece continuar el patrón anterior, con departamentos de estructura económica más tradicional, más consolidada y mayor riqueza individual, que presentan también una heterogeneidad mayor en el reparto de la misma (Cuadro 5). En tanto, otros departamentos de más reciente ocupación y más ligados al proceso de colonización (Colón, Diamante, en parte Nogoyá) han acortado la distancia que los separaba de ellos, mostrando los efectos de un claro ciclo de acumulación por parte de algunos de sus agentes. Sin duda, se ha ido concretando allí el proceso de consolidación de la propiedad, y las nuevas actividades productivas han brindado al parecer en las décadas previas buenas oportunidades de ganancia. 
Es significativo, asimismo, analizar aquellos departamentos en los que se destaca un aumento proporcional mayor en el número de propietarios; mientras era más esperable que ello ocurriera en los de ocupación más antigua y más poblados (Paraná, Gualeguaychú, por ejemplo), resulta bastante novedoso encontrar también evoluciones muy positivas en áreas de más reciente ocupación, como Rosario del Tala o Villaguay. Pero si, en el último caso, el cambio puede muy bien deberse al proceso de colonización agrícola encarado allí desde inicios de la década de 1880, en Rosario del Tala una dotación de recursos más modesta derivó en la constitución de unidades más pobres, como parece entreverse del descenso del valor mínimo por unidad. Asimismo, en los departamentos más antiguos y más ricos, cuyas tierras habían ido tomando valor antes, la estructura productiva existente y los intereses creados en torno a la misma pueden haber ofrecido menos oportunidades para un cambio radical de la pauta productiva, pero pueden también haberlas potenciado para mejorar la eficiencia en el rubro adoptado de antemano.

Sin duda, la colonización agrícola introdujo un elemento de ruptura importantísimo en las áreas de ocupación más precaria y de tierras con valor inicial más bajo; por comparación, el rendimiento por hectárea de la ganadería vacuna tradicional era en ellas mucho menor. Pero, a comienzos de la última década del siglo XIX, la brecha de productividad entre la actividad agrícola intensiva y la ganadería debió irse reduciendo conforme esta última fue incorporando mejoras técnicas, reduciendo la vocación extensiva que la había caracterizado anteriormente. Este proceso, iniciado en torno al ovino refinado, para los años finales del siglo XIX ya estaba lo suficientemente extendido, e incluso comenzaba a intensificarse con la concreción del ciclo de mejoras en torno al vacuno. De ese modo, la valorización de las tierras por efecto de esos cambios debió de atenuar sensiblemente la conveniencia de pasarse al rubro agrícola, aunque no la de fragmentar parte de las tenencias a fin de lograr concentrar un mayor grado de inversión en el área remanente. Así, la introducción de las nuevas actividades agrícolas debió de ser menos conveniente en ciertas zonas de ocupación más antigua, cuya orientación ganadera debió permanecer, incorporando, eso sí, mejoras técnicas, animales de razas de mayor rendimiento y un grado más intenso de uso de los recursos. Esto en parte podría estar evidenciándose en la menor proporción de superficie colonizada en los departamentos más ricos, como Gualeguay, Gualeguaychú y Uruguay, si bien la gran extensión del segundo de ellos morigera el impacto de esas cifras $^{34}$. En cualquier caso, de ello puede deducirse que la

34 Entre un 8 y un 12 por 100 de la superficie aprovechable, es decir, deduciendo anegadizos. Proporciones inferiores a ésas sólo se encuentran en los departamentos más pobres y alejados, como La Paz o Feliciano, donde, por otra parte, los suelos son mucho menos aptos para la práctica agrícola. El porcentaje de área colonizada según el censo de 1895, en De la Fuente, Carrasco y Martinez (1898), t. II, pp. 652 y ss.; la superficie productivamente aprovechable por departamento, en Raña (1904). 
anterior tendencia que asimilaba zonas antiguas con producción ganadera y mayor riqueza, y áreas agrícolas más nuevas y más pobres, ha comenzado en alguna medida a desdibujarse y mutar hacia 1892, mostrando la emergencia de un nuevo patrón, bajo el cual la complementación de ambas actividades será cada vez más patente, en la medida en que la expansión agrícola se derramaba fuera del ámbito de las colonias y se introducía en las estancias, como ocurrirá claramente desde inicios del siglo XX.

Es de advertir, asimismo, que algunos departamentos parecen mantener una tendencia estructural de menores posibilidades de acumulación, en tanto las mayores fortunas privadas siguen siendo, en ambos años, muy pequeñas en comparación con las correspondientes a los otros departamentos (como ocurrió con Rosario del Tala o Victoria). Ello nos indica que en esa evolución deben tenerse en cuenta las limitaciones que imponían, tanto el medio ecológico como los recursos disponibles, para encarar las nuevas estrategias productivas; recursos tanto físicos como financieros, en tanto que es más probable que quienes tuvieran dinero buscaran invertirlo en las áreas de rentabilidad más segura en detrimento de otras zonas que, aunque de menor coste de adquisición, presentaban los inconvenientes propios de áreas cuya peor dotación exigía una mayor tasa de inversión por hectárea y sometía la producción a un riesgo mayor ante las contingencias ambientales. Lo contrario ocurría en las tierras más ricas, adaptadas a actividades multipropósito, como Gualeguay o Gualeguaychú.

Por tanto, a pesar de los matices introducidos - en cuanto a la existencia de nuevos grados de equidad espacial de la riqueza justificados al menos en parte por los cambios en la estructura productiva-, todavía en 1892 se mantienen en buena medida las tendencias que ya se registraban casi dos décadas antes: las zonas del oriente, de ocupación más antigua y orientación más ganadera, siguen poseyendo una distribución más heterogénea de la riqueza; las zonas "nuevas", pobladas más recientemente (como por ejemplo Diamante, Villaguay, Federación, Rosario del Tala o Victoria) poseen una distribución más homogénea, ello independientemente del grado de éxito que hayan tenido en la aventura de encarar el cambio productivo hacia actividades más intensivas. Así, las tendencias del reparto de la riqueza inmobiliaria no parecen haberse alterado allí sustancialmente a pesar de su recorrido económico. Lo cual marca quizá dificultades para encarar la fragmentación de las tenencias, en tanto una dotación mínima estaría todavía ligada al suceso productivo, mientras que en las áreas más aptas esto no ocurriría. 


\section{La riqueza personal por rangos}

A pesar de la muy leve variación que, entre 1874 y 1892, muestran los índices de Gini y de las curvas de Lorenz, si analizamos la evolución de los diversos rangos de la riqueza aparecen movimientos bastante consistentes. Por ello, hemos agrupado a los propietarios en rangos que van hasta un máximo que duplica la base respectiva; partiremos, así, desde una primera categoría con un rango entre 1 y 1.204 pesos moneda nacional ${ }^{35}$, que se continuará con otra entre 1.205 y 2.407, y las subsiguientes en la misma proporción. Para el análisis de los casos hemos agrupado nuevamente las tenencias de varios propietarios que poseían tierras en distintos departamentos, volviendo así a los 973 propietarios de 1874 y a los 2.253 de 1892 .

Como puede comprobarse (Cuadros 6 y 7), si bien los distintos rangos parecen haber mantenido en términos generales su proporción de valor sobre el total (lo que se refleja en los índices de Gini), en realidad esa permanencia oculta un fuerte proceso de pérdida de valor promedio por propietario entre 1874 y 1892 en los rangos más opulentos y de concentración en los de menor dimensión. El primer fenómeno refleja un intenso proceso de partición de las grandes tenencias fundiarias, sin duda ligado al desmoronamiento de los tradicionales procesos productivos en torno a la ganadería vacuna, que iban perdiendo sus rasgos de extrema extensividad. Una simple mirada a los mapas catastrales de 1874 y 1892 muestra claramente que los grandes propietarios tradicionales de la primera de esas fechas han desaparecido en buena parte durante la segunda; otros han reducido en forma drástica sus tenencias, tanto por partición de herencias como por venta. Los ejemplos más conspicuos al respecto son los de las extensas propiedades de la familia Urquiza y las de Ricardo López Jordán.

Así, asediadas por el constante y rápido proceso de valorización de la tierra, las grandes explotaciones entrerrianas se vieron sometidas a una dura disyuntiva: encarar una costosa capitalización que revirtiera, con mayores rendimientos futuros, la rentabilidad decreciente de las actividades tradicionales, o vender progresivamente partes de la propiedad a fin de obtener así los fondos necesarios para el cambio productivo, encarado a una escala mucho menor que antaño. Esta última solución, la más viable, parece haber sido también la escogida preferentemente por la mayor parte de los grandes propietarios entrerrianos en el último cuarto del siglo XIX. En una economía crónicamente escasa de capitales, muy pocos hubieran podido sin duda soportar los grandes gastos de un intenso proceso de inversión sobre unidades de inmensa escala operativa, o la consiguiente situación de varios años de trabajo a pérdida o con márgenes de rentabilidad muy bajos, consecuencia necesaria de todo proceso de esas características. La venta de parte de sus tierras con el fin de obtener

\footnotetext{
35 Equivalentes a 0,4 y 500 pesos bolivianos, siendo el valor mínimo original en realidad de 118.
} 


\section{CUADRO 6}

EVOLUCIÓN DE LOS CAPITALES EN TIERRA POR RANGOS, ENTRE RÍOS, 1874-1892 (en pesos moneda nacional de 1895)

\begin{tabular}{|c|c|c|c|c|c|c|}
\hline \multicolumn{7}{|c|}{ Año 1874} \\
\hline \multicolumn{2}{|c|}{ Rangos } & \multirow{2}{*}{ Propietarios } & \multirow{2}{*}{$\begin{array}{c}\text { Porcentaje } \\
\text { sobre total de } \\
\text { propietarios }\end{array}$} & \multirow{2}{*}{ Valor total } & \multirow{2}{*}{$\begin{array}{l}\text { Porcentaje } \\
\text { sobre } \\
\text { valor total }\end{array}$} & \multirow{2}{*}{$\begin{array}{c}\text { Valor } \\
\text { promedio }\end{array}$} \\
\hline De... & Hasta... & & & & & \\
\hline 1 & 1.204 & 53 & 5 & 41.852 & 0 & 737 \\
\hline 1.205 & 2.407 & 68 & 7 & 123.333 & 1 & 1.737 \\
\hline 2.408 & 4.815 & 171 & 18 & 633.103 & 3 & 3.558 \\
\hline 4.816 & 9.630 & 254 & 26 & 1.828 .994 & 8 & 6.640 \\
\hline 9.631 & 19.260 & 208 & 21 & 2.821 .232 & 13 & 12.754 \\
\hline 19.261 & 38.519 & 120 & 12 & 3.279 .273 & 15 & 26.118 \\
\hline 38.520 & 77.038 & 55 & 6 & 2.943 .955 & 13 & 51.200 \\
\hline 77.039 & 154.077 & 30 & 3 & 3.226 .622 & 14 & 106.529 \\
\hline 154.078 & 308.154 & 7 & 1 & 1.416 .388 & 6 & 202.340 \\
\hline 308.155 & 616.307 & 5 & 1 & 2.175 .439 & 10 & 435.230 \\
\hline 616.308 & 1.232 .614 & 1 & 0 & 851.970 & 4 & 851.970 \\
\hline \multicolumn{2}{|c|}{ Más de 1.232.614 } & 1 & 0 & 2.953 .081 & 13 & 2.953 .081 \\
\hline \multicolumn{2}{|c|}{ TOTAL } & 973 & \multicolumn{3}{|c|}{22.295 .243} & \\
\hline \multicolumn{7}{|c|}{ Año 1892} \\
\hline \multicolumn{2}{|c|}{ Rangos } & \multirow{2}{*}{ Propietarios } & \multirow{2}{*}{$\begin{array}{c}\text { Porcentaje } \\
\text { sobre total de } \\
\text { propietarios }\end{array}$} & \multirow{2}{*}{ Valor total } & \multirow{2}{*}{$\begin{array}{l}\text { Porcentaje } \\
\text { sobre } \\
\text { valor total }\end{array}$} & \multirow{2}{*}{$\begin{array}{c}\text { Valor } \\
\text { promedio }\end{array}$} \\
\hline De... & Hasta... & & & & & \\
\hline 1 & 1.204 & 7 & 0 & 7.057 & 0 & 1.008 \\
\hline 1.205 & 2.407 & 43 & 2 & 82.122 & 0 & 1.910 \\
\hline 2.408 & 4.815 & 120 & 5 & 439.241 & 0 & 3.660 \\
\hline 4.816 & 9.630 & 334 & 15 & 2.375 .639 & 2 & 7.113 \\
\hline 9.631 & 19.260 & 521 & 23 & 7.325 .584 & 5 & 14.061 \\
\hline 19.261 & 38.519 & 525 & 23 & 14.447 .783 & 10 & 27.520 \\
\hline 38.520 & 77.038 & 340 & 15 & 18.266 .039 & 13 & 53.724 \\
\hline 77.039 & 154.077 & 204 & 9 & 22.157 .825 & 16 & 108.617 \\
\hline 154.078 & 308.154 & 86 & 4 & 18.685 .857 & 13 & 217.277 \\
\hline 308.155 & 616.307 & 47 & 2 & 20.209 .338 & 14 & 429.986 \\
\hline 616.308 & 1.232 .614 & 16 & 1 & 12.240 .858 & 9 & 765.054 \\
\hline \multicolumn{2}{|c|}{ Más de 1.232.614 } & 10 & 0 & 26.054 .892 & 18 & 2.605 .489 \\
\hline \multicolumn{2}{|c|}{ TOTAL } & 2.253 & & 142.292 .233 & & \\
\hline
\end{tabular}

Fuentes: González (1874) y Nolte (1892). 


\section{CUADRO 7}

COMPARACIÓN DE LOS CAMBIOS DE LOS CAPITALES EN TIERRA POR RANGOS,

ENTRE RÍOS, 1874-1892

(en pesos moneda nacional de 1895)

\begin{tabular}{|c|c|c|c|c|c|c|c|}
\hline \multicolumn{2}{|c|}{ Rangos } & \multicolumn{2}{|c|}{ Cantidad propietarios } & \multicolumn{2}{|c|}{ Valor promedio } & \multicolumn{2}{|c|}{$\begin{array}{l}\text { Porcentaje valor franja } \\
\text { sobre valor total }\end{array}$} \\
\hline De... & Hasta... & $\begin{array}{c}\text { Aumento } \\
1874-92\end{array}$ & $\begin{array}{l}\text { Porcentaje } \\
\text { sobre total }\end{array}$ & $\begin{array}{c}\text { Aumento } \\
1874-92\end{array}$ & $\begin{array}{l}\text { Porcentaje } \\
\text { sobre valor } \\
\text { de } 1874\end{array}$ & 1874 & 1892 \\
\hline 1 & 1.204 & -46 & -4 & 271 & 37 & 0 & 0 \\
\hline 1.205 & 2.407 & -25 & -2 & 173 & 10 & 1 & 0 \\
\hline 2.408 & 4.815 & -51 & -4 & 103 & 3 & 3 & 0 \\
\hline 4.816 & 9.630 & 80 & 6 & 472 & 7 & 8 & 2 \\
\hline 9.631 & 19.260 & 313 & 24 & 1.307 & 10 & 13 & 5 \\
\hline 19.261 & 38.519 & 405 & 32 & 1.401 & 5 & 15 & 10 \\
\hline 38.520 & 77.038 & 285 & 22 & 2.524 & 5 & 13 & 13 \\
\hline 77.039 & 154.077 & 174 & 14 & 2.088 & 2 & 14 & 16 \\
\hline 154.078 & 308.154 & 79 & 6 & 14.937 & 7 & 6 & 13 \\
\hline 308.155 & 616.307 & 42 & 3 & -5.244 & -1 & 10 & 14 \\
\hline 616.308 & 1.232 .614 & 15 & 1 & -86.916 & -10 & 4 & 9 \\
\hline \multicolumn{2}{|c|}{ Mas de 1.232.614 } & 9 & 1 & -347.592 & -12 & 13 & 18 \\
\hline \multicolumn{2}{|c|}{ TOTAL } & 1.280 & & & & & \\
\hline
\end{tabular}

Fuentes: González (1874) y Nolte (1892).

dinero para transformar lo restante en unidades de explotación más intensiva (ya fuera a través de una ganadería refinada o de la agricultura especializada) parece haberse constituido en una de las claves de la supervivencia productiva entre los grandes propietarios.

Sin embargo, esos cambios no impidieron que su participación en el total del valor fundiario aumentara, en buena parte a expensas de la proporción ocupada por las unidades más pequeñas. Esto se verifica en el intenso descenso de la cantidad de propietarios de valores de menos de 4.816 pesos. Aun cuando el valor promedio por tenencia de esas franjas aumentó, la proporción del valor total poseído por las mismas se redujo. Es decir, en estos rangos ocurrió un proceso inverso al que afectó a los más grandes: probablemente por problemas derivados de un contexto de creciente competitividad, algunos propietarios de pequeñas explotaciones debieron despren- 
derse de ellas, posibilitando a otros constituir unidades más viables con su compra. No obstante, hemos dicho anteriormente que nuestra fuente subrepresenta a los sectores más bajos de la sociedad, en tanto muchos de ellos no accedieron a la propiedad fundiaria. Asimismo, la circunstancia de no poder evaluar la propiedad más dividida de las colonias agrícolas impone una importante limitación a nuestras consideraciones. Si bien sería muy arriesgada la deducción de inferencias definitivas a partir de tan pocos datos, éstos parecieran indicar que los rangos más consistentes de la explotación familiar habría que buscarlos en las nuevas áreas agrícolas de la provincia, y no entre nuestra base de propietarios. Es probable que sea justamente en las colonias agrícolas y en las áreas cercanas a los pueblos y los ejidos urbanos donde las explotaciones familiares fueran proporcionalmente más abundantes, y que los datos de nuestros cuadros reflejen sobre todo a ciertas unidades de tipo ganadero, e incluso ligadas a formas tradicionales de explotación, antes que al creciente sector farmer de la provincia, cuya existencia de todos modos aparece aquí en alguna forma sugerida.

El escalón siguiente (entre 4.816 y 9.630 pesos), que comprende aproximadamente a tenencias de entre 250 y 500 hectáreas, corresponde con todo a una producción familiar ampliada con contratación de mano de obra, cuyo peso se ha mantenido a pesar de un descenso muy considerable en su porción sobre el valor total. Es de recordar, además, que desde hacía unos años la provincia estaba soportando no sólo las duras consecuencias de la crisis económica y financiera de 1890, sino una serie de calamidades climáticas e invasiones de insectos destructivos, como la langosta (acridium peregrinum) ${ }^{36}$. Es indudable que estos fenómenos desempeñaron un papel importante en los problemas experimentados por buena parte de los productores, y quizá también en la tendencia a la concentración que se muestra aquí.

Los rangos que van entre los 19.261 y 308.154 pesos moneda nacional, corresponden sin duda a una capa de empresarios más capitalizados, cuyo liderazgo del proceso de cambio productivo debió de haber sido consistente. Si bien no contamos con datos sistemáticos acerca de su dotación de capital, algunos indicios aislados son de por sí elocuentes. Considerando un precio promedio de la hectárea de 20 pesos de moneda nacional, estos rangos equivaldrían aproximadamente a tenencias de entre 1.000 y 15.000 hectáreas; si miramos los nombres de algunos de esos propietarios, nos encontraremos con conocidos empresarios agrarios, venidos en buena parte desde otras áreas más dinámicas. Por ejemplo Eduardo Casey, quien poseía alrededor de 8.100 hectáreas en Federación, en el distrito Tatutí; Ignacio Pirovano, quien poseía 16.200 hectáreas en Villaguay; Juan B. Mihura, con alrededor de 4.000 en el distrito Sauce, en Nogoyá, uno de los más caros del departamento, y otras 5.400 en Montoya, en Victoria, donde instaló un criadero de caballos de raza que, ya en 1887, 


\section{GRÁFICO 2}

ACUMULACIÓN DE CUOTAS POR DECILES EN 1874 Y 1892

(porcentaje)

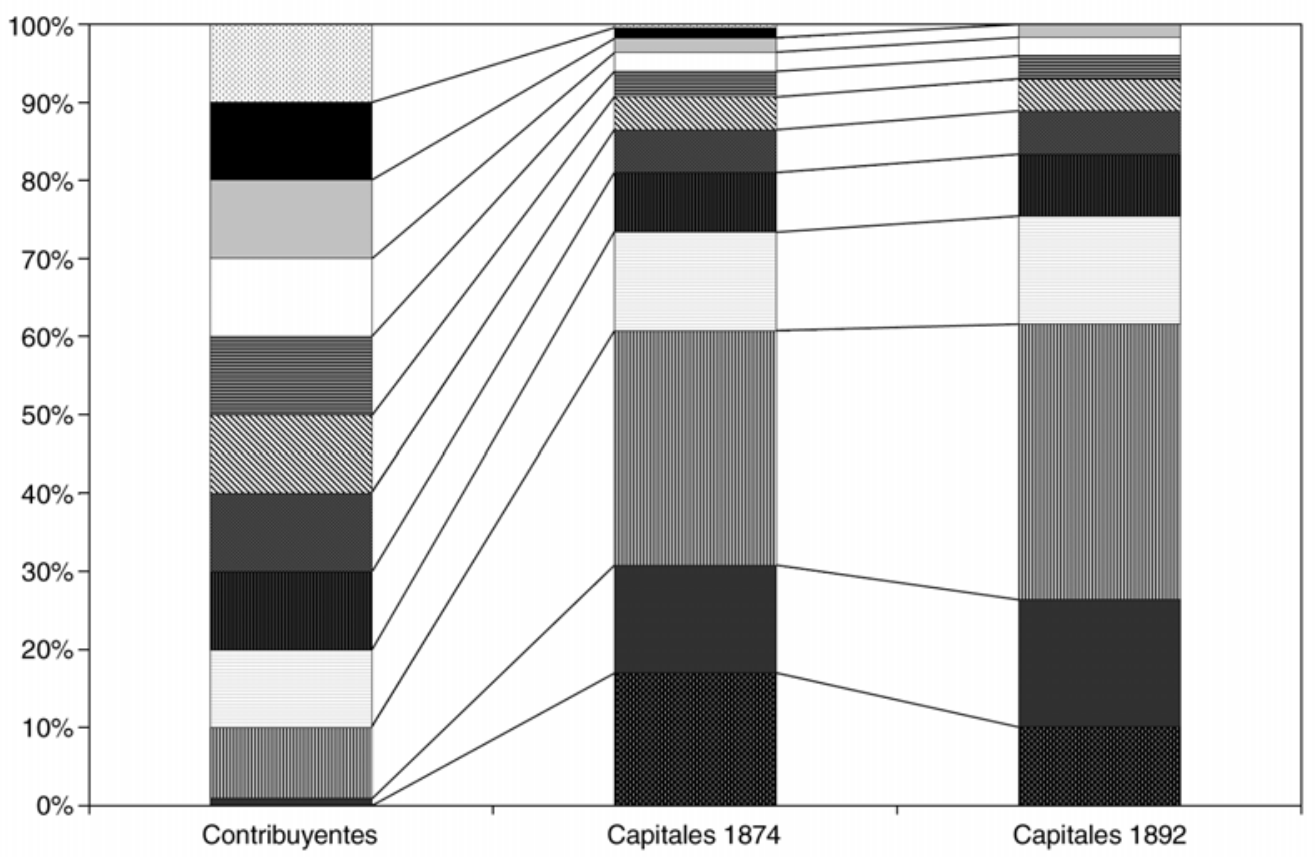

Fuentes: González (1874) y Nolte (1892).

le valió un primer premio en la Exposición General Provincial ${ }^{37}$. Más grandes, pero también cerca de esos rangos, se encuentran personajes como Bernardo de Irigoyen, quien poseía 37.800 hectáreas en el Yuquerí, en Concordia; este multifacético personaje encaró la fundación de colonias agrícolas en Santa Fe y Entre Ríos, y fue uno de los miembros más destacados del grupo de empresarios que lideró el proceso del refinamiento del vacuno en Buenos Aires ${ }^{38}$. Si bien muchos de estos nuevos propie-

37 Rodríguez (1972).

38 Fundó la colonia Irigoyen en Santa Fe, con 8.750 hectáreas, y Adela, en Entre Ríos, con 5.400; además, ofrecía en esa provincia ya desde cinco años antes concesiones de terreno a 100 pesos oro por cuadra en sus campos de Concordia, pagables en anualidades de 20 pesos con un interés anual del 10 por 100 . Si bien los precios eran considerados altos, se trataba de tierras muy buenas para la actividad agrícola, estando además situadas a la vera del río Uruguay, lo cual las ponía en rápida comunicación con los mercados del sur. Van Bruyssel (1888), p. 215; Raña (1904), pp. 295 y ss.; y Sesto (2005). 
tarios llegaron a poseer tierras en la provincia comprándolas, otros accedieron a las mismas vinculándose con antiguas familias locales por medio de alianzas matrimoniales. Así, el general Luis María Campos, cuyo establecimiento ganadero cosechó diversos premios en la exposición rural de 1887, se había casado con Justa Dolores de Urquiza, hija de Justo José de Urquiza, que había sido Presidente de la República, accediendo así a una importante fracción de campos. Historias similares podrían relatarse, por ejemplo, de los Sáenz Valiente ${ }^{39}$.

En definitiva, la comparación por deciles (Gráfico 2) confirma lo que hemos venido diciendo: entre 1874 y 1892 los rangos intermedios-altos parecen haber ganado peso a expensas del 10 por 100 más concentrado, así como también de los sectores de menor dimensión.

\section{Conclusiones}

Entre las décadas de 1870 y 1890, que fueron de rápido despegue para el crecimiento económico de la región pampeana, el desempeño entrerriano fue modesto en comparación con el de las otras provincias vecinas. Por lo cual, si allí la tierra se comenzó a valorizar en forma intensa, eso sucedió en buena parte debido al propio aumento poblacional más que a un salto importante en la productividad. Esa circunstancia parece haber respondido a ciertas limitaciones que debió enfrentar el proceso de transformación de la producción rural hacia pautas más intensivas en el uso de los recursos, centradas en el ganado refinado y la agricultura especializada.

Esas limitaciones de productividad habrían estado en buena medida vinculadas a la dotación ecológica de la provincia, no siempre apta para las renovadas actividades asociadas a la exportación. Además, no debe olvidarse el peso de determinadas pautas institucionales de acceso a la tierra, que si durante la primera mitad del siglo habían resultado funcionales en la etapa de producción extensiva, con la implementación efectiva de las leyes de tierras de 1861 se creó un contexto institucional que ayudó a consolidar la gran propiedad y a aumentar desmesuradamente los precios inmobiliarios, fenómeno que derivó en dificultades crecientes para la transformación productiva posterior.

Es probable que las opciones mercantiles abiertas a los empresarios rurales de esta provincia también hayan constituido un freno a esos procesos de innovación, en tanto que en sus exportaciones continuaron teniendo mucho peso los mercados que demandaban bienes tradicionales, en esencia derivados ganaderos de la ya antigua 
manufactura del saladero. Asimismo, la crónica escasez de financiamiento debe haber incluso profundizado esta situación, en tanto limitó la toma de riesgo para la inversión y la renovación a largo plazo.

Todo aquello derivó en que los entrerrianos no se encontraran, hacia finales del siglo XIX, entre los principales beneficiarios de la notable expansión rural argentina de las décadas previas, que había transformado en forma completa vastas áreas de la región pampeana. E, incluso, como mostramos, el crecimiento experimentado en el interior de la provincia fue muy disímil según la zona. Es lógico que hayan crecido más rápidamente los departamentos mejor dotados para la práctica de las nuevas actividades, como Gualeguay o Gualeguaychú; pero también tuvo su importancia la experiencia productiva previa de esas áreas y la dotación respectiva de capital, o la capacidad de generarlo, como lo demuestran sobre todo los ejemplos de adaptación en Colón y Diamante.

De todos modos, debe destacarse el aumento general en la cantidad de propietarios rurales, que superó el incremento poblacional, lo que habla a las claras de que, más allá del rezago económico — en relación a otras provincias-, también hubo generación de oportunidades de acceso a la propiedad fundiaria durante el período, algo que sin duda explica, al menos en buena parte, la significativa inmigración que recibió Entre Ríos.

En lo que respecta a los cambios en la distribución espacial de la riqueza inmobiliaria rural, las distintas pautas de crecimiento en el interior de los diferentes departamentos no parecen haber alterado las tendencias preexistentes. Por tanto, el mayor o menor crecimiento no se correlacionó así, necesariamente, con una mayor o menor heterogeneidad en la distribución de la tierra. Lo cual nos estaría indicando, por un lado, que el contexto institucional y la estructura más bien inequitativa de la propiedad existentes en el punto de partida habrían condicionado en buena medida la evolución posterior de la capacidad de acortar la brecha entre los estratos más y menos concentrados. Por otro lado, el hecho ya mencionado de que la valorización de la tierra se debiera en buena parte al crecimiento poblacional, y no tanto a un incremento sustancial en la productividad, tendió también a moderar la capacidad transformadora de la inserción de los nuevos rubros productivos. Por lo señalado, entonces, en los departamentos de vieja colonización y con propiedad consolidada tempranamente parecen sostenerse las distancias mayores, en tanto en la nueva frontera los índices muestran mayor equidad. Asimismo, emerge un patrón por el cual aquellas zonas más consolidadas de vieja frontera ganadera tendían a ser más desiguales, y, al mismo tiempo, acumulaban mayor riqueza, en tanto que las zonas agrícolas eran más equitativas, pero más pobres en términos globales. Por consiguiente, la distribución de la riqueza inmobiliaria rural durante este período del siglo XIX no parece estar relacionada solamente con el crecimiento económico, sino que, como hemos visto, hubo otras variables muy importantes que también la determinaron: los 
condicionantes institucionales, la dotación de factores ambientales, los distintos ciclos de puesta en producción de la tierra y la evolución del costo relativo de los factores de producción.

De todos modos, más allá de las grandes tendencias generales de la provincia que muestran rasgos estáticos, la evolución de la riqueza personal y de los patrones de acumulación sí parecen experimentar cambios, que hubieran quedado ocultos al análisis si sólo nos hubiéramos fiado de los índices de Gini o de las curvas de Lorenz. Si bien los procesos de incremento poblacional tuvieron en ella un papel importante, es de destacar que por sí mismos no son suficientes para explicar los cambios en las proporciones de la riqueza inmobiliaria según las distintas capas de propietarios. De ahí que para comprender cabalmente esta cuestión se debe resaltar la importancia de las estrategias de gestión rural utilizadas durante este período. Al respecto, los datos muestran que hubo un reforzamiento relevante de un sector "empresarial" de escala intermedia-grande, aparentemente más abierto a las nuevas pautas de modernización y a la inversión de riesgo, y que intentaba aplicarlas a diversos niveles y en distinta dimensión, según fueran los recursos con los que pudiera contar o las mayores o menores posibilidades de la coyuntura.

Aquel sector intermedio-grande creció en su dotación fundiaria a expensas de los tradicionalmente más grandes propietarios, cuya participación y promedio de riqueza inmobiliaria en este período disminuyeron con bastante intensidad. Y también se expandieron tomando una parte de las tenencias de los propietarios de menor dimensión. De ese modo, la fragmentación y enajenación de las viejas propiedades grandes y pequeñas se constituyó en la vía más adecuada para superar las restricciones de la producción rural extensiva tradicional, que en ese nuevo contexto ya no era tan viable debido a sus rendimientos decrecientes.

Pese al fortalecimiento de aquellos sectores intermedios, más dinámicos, es probable que los mismos también experimentaran una creciente estratificación interna. Dado que en las nuevas condiciones de producción había variado sustancialmente la potencialidad del uso de los recursos naturales de acuerdo a la inversión de capital, esta última era ahora la clave principal de la competitividad, verificable sobre todo en la dotación individual de maquinaria e instalaciones.

En aquella evolución, asimismo, hubo luces menos brillantes, pues comenzó a diferenciarse también, por ejemplo, un sector de propietarios de dimensión mediana a baja que parece responder todavía a pautas productivas remanentes de la vieja tradición ganadera extensiva y descapitalizada. En tanto, otro sector con algo más de recursos incrementaba notablemente su número de individuos; pero su promedio de riqueza permaneció prácticamente estancado, lo cual, más allá de la fuerte distorsión traída por los procesos inversos de auge económico en la década de 1880 y profunda crisis a finales de la misma e inicios de la siguiente, podría quizá deberse a limitaciones en su capacidad de acceso a medios de renovación productiva, en esencia al crédito. 
Finalmente, el sector de los pequeños propietarios familiares parece escapar casi plenamente a estos registros, dado que su número es significativamente bajo, no variando su participación entre los años examinados. Por lo cual, puede colegirse que el mismo estaba, hacia finales del siglo, asociado fundamentalmente a las colonias agrícolas y al sector de arrendatarios agrarios, cuyas características y evolución, de ese modo, no nos es posible entrever en este estudio.

\section{Bibliografía}

ÁLVAREZ, Juan (1929): Temas de historia económica argentina, Buenos Aires, El Ateneo. ARGENTINA, DIRECCIÓN GENERAL DE ESTADÍSTICA (1895): Anuario de la Dirección General de Estadística correspondiente al año 1894, Buenos Aires, Compañía Sudamericana de Billetes de Banco.

ARGENTINA, PROVINCIA DE ENTRE RÍOS, DEPARTAMENTO GENERAL DE ESTADÍSTICA (1897): Anuario del Departamento general de Estadística de la Provincia de Entre-Ríos correspondiente al año 1896, Paraná, El Paraná.

ARGENTINA, PROVINCIA DE ENTRE RÍOS, OFICINA GENERAL DE ESTADÍSTICA (1888): Resúmenes generales y preliminares en cifras absolutas del censo agrícola y ganadero levantado a fines de 1887 y principios de 1888..., Paraná, Tip. Lit. Nacional a Vapor.

ATKINSON, Anthony (1975): The economics of inequality, Oxford, Clarendon Press.

BANZATO, Guillermo; BLANCO, Graciela; BLANCO, Mónica, y FERREYRA, Ana Inés (comps.) (2007): “Dossier: Acceso y tenencia de la tierra en Argentina. Enfoques locales y regionales, siglos XVIII-XX", Mundo Agrario, 14 (http://www.mundoagrario.unlp.edu.ar/mundo_agrario/numeros/numero14/copy2_of_index_html), acceso noviembre 2007.

BARSKY, Osvaldo, y DJENDEREDJIAN, Julio (2003): Historia del capitalismo agrario pampeano. Tomo I. La expansión ganadera hasta 1895, Buenos Aires, Siglo XXI.

BARSKY, Osvaldo, y GELMAN, Jorge (2001): Historia del agro argentino, Buenos Aires, Grijalbo Mondadori.

BAVIO, Ernesto et al. (1893): La Provincia de Entre-Ríos. Obra descriptiva..., Paraná, Tipografía, Litografía y Encuadernación "La Velocidad".

CHIARAMONTE, José Carlos (1970): Nacionalismo y liberalismo económicos en la Argentina, 1860-1880, Buenos Aires, Solar-Hachette.

CORTÉS CONDE, Roberto (1979): El progreso argentino, Buenos Aires, Sudamericana.

-(1997): La economía argentina en el largo plazo (siglos XIX y XX), Buenos Aires, Sudamericana.

DA SILVA, José Gentil (1965): "Cálculos retrospectivos del producto", Desarrollo económico, 4, 16, pp. 427-447. 
DE LA FUENTE, Diego (dir.) (1872): Primer censo de la República Argentina verificado en los días 15, 16 y 17 de septiembre de 1869, Buenos Aires, Imprenta del Porvenir.

DE LA FUENTE, Diego; CARRASCO, Gabriel, y MARTÍNEZ, Arturo (1898): Segundo censo de la República Argentina. Mayo 10 de 1895, Buenos Aires, Taller Tipográfico de la Penitenciaría Nacional.

DÍAZ ALEJANDRO, Carlos (1975): Ensayos sobre la Historia Económica Argentina, Buenos Aires, Amorrortu.

DJENDEREDJIAN, Julio (2003): Economía y sociedad en la Arcadia criolla. Formación y desarrollo de una sociedad de frontera en Entre Ríos, 1750-1820, tesis doctoral inédita, Universidad de Buenos Aires.

—(2004): “¿Un aire de familia? Producción ganadera y sociedad en perspectiva comparada: las fronteras rioplatenses a inicios del siglo XIX", Jahrbuch für Geschichte Lateinamerikas, 41, pp. 247-273.

FELQUER, José Francisco, y MOREIRA BAHLER DE FELQUER, Laura (1962): Geografía de Entre Ríos (física, biológica y humana), Paraná, Imprenta Nueva Impresora.

FERNÁNDEZ, Aurelio (1896): Prontuario informativo de la Provincia de Santa Fe, Rosario, La Minerva.

FRANK, Zephyr (2005): “Wealth holding in southeastern Brazil, 1815-1860", Hispanic American Research Review, 85, 2, pp. 223-258.

GALLO, Ezequiel (1983): La pampa gringa. La colonización agrícola en Santa Fe (18701895), Buenos Aires, Sudamericana.

GELMAN, Jorge, y SANTILLI, Daniel (2006): De Rivadavia a Rosas. Desigualdad y crecimiento económico, Buenos Aires, Siglo XXI y Universidad de Belgrano.

GONZÁlEZ, Melitón (1874): Carta topográfica de la Provincia de Entre Ríos con la demarcación de terrenos de particulares adoptada por el Excmo. Gobierno de la Provincia, Buenos Aires, Hardoy \& Schleisinger.

GUDMUNSON, Lowell (1983): “Costa Rica before Coffee: Occupational Distribution, Wealth inequality, and Elite society in the village economy of the 1840s", Journal of Latin American Studies, 15, 2, pp. 427-452.

HUDSON, Damián (dir.) (1867): Registro estadístico de la República Argentina. 1865. Tomo segundo, Buenos Aires, J. A. Bernheim.

HUERGO, Juan B. (1887): "Informe sobre las lanas argentinas en Europa”, Boletín del Departamento Nacional de Agricultura, 10, pp. 237-239.

JOHNSON, Lyman (1994): "Distribution of Wealth in nineteenth century Buenos Aires province: the Issue of Social Justice in a changing Economy", en ANDRIEN, Kenneth, y JOHNSON, Lyman (eds.), The political economy of Spanish America in the age of Revolution 1750-1850, Alburquerque, University of New Mexico Press, pp. 197-213.

KAERGER, Karl (2004 [1897]): La agricultura y la colonización en Hispanoamérica. Los estados del Plata, Buenos Aires, Academia Nacional de la Historia. 
KUZNETS, Simon (1966): Modern Economic Growth, New Haven, Yale University Press.

LANDES, David (1998): The wealth and poverty of nations. Why some are so rich and some so poor, New York-London, W. W. Norton \& Company.

MACCHI, Miguel E. (1971): Urquiza el saladerista, Buenos Aires, Macchi.

MILOSLAVICH DE ÁLVAREZ, María del Carmen (1988): Hace un largo fondo de años. Genealogía uruguayense, Concepción del Uruguay, s/e.

MULHALL, Michael G., y MULHALL, Edward T. (1885): Handbook of the River Plate. Fifth Edition, Buenos Aires y Londres, Mulhall y Trübner.

-(1892): Handbook of the River Plate. Sixth Edition, Buenos Aires y Londres, M. G. y E. T. Mulhall, Kegan Paul y Trench \& Co.

NAPP, Ricardo (1876): La República Argentina, Buenos Aires, Sociedad Anónima.

NOLTE, Ernst (ed.) (1892): Plano catastral de la provincia de Entre-Ríos construido según los datos más recientes, Buenos Aires, Nolte.

RAÑA, Eduardo S. (1904): Investigación agrícola en la Provincia de Entre Ríos, Buenos Aires, Imprenta de M. Biedma é Hijo.

RODRÍGUEZ VAGARÍA DE ARCE, María E. (1972): Aspectos socio-económicos del desarrollo de Entre Ríos 1868-1888, Paraná, s/e.

SÁBATO, Hilda (1989): Capitalismo y ganadería en Buenos Aires: la fiebre del lanar, 18501890, Buenos Aires, Sudamericana.

SCHMIT, Roberto (2004): Ruina y Resurrección en tiempos de guerra. Sociedad, Economía y Poder en el Oriente entrerriano posrevolucionario, 1810-1852, Buenos Aires, Prometeo.

SESTO, Carmen (2005): Historia del capitalismo agrario pampeano. Tomo II. La vanguardia ganadera bonaerense, 1856-1900, Buenos Aires, Siglo XXI-UB.

VAN BRUYSSEL, Ernst (1888): La République Argentine, Bruxelles, Librairie Européenne C. Muquardt-Th. Falk.

VÁZQUEZ DE LA MORENA, Manuel (1886): “Condiciones económicas de Entre Ríos", Boletín del Departamento Nacional de Agricultura, t. 10.

WEYNE, Olga (1988): Descripción de un ciclo de colonización agrícola. Entre Ríos entre 1870 y 1914, Buenos Aires, Instituto Torcuato Di Tella, Documento de Trabajo 104.

WILLIAMSON, Jeffrey, y LINDERT, Peter (1980): American inequality. A macroeconomic History, New York, Academic Press.

WILLIAMSON, Jeffrey (2002): “Land, Labor and Globalization in the Third World, 1870 1940", The Journal of Economic History, 62, 1, pp. 55-85 